\title{
Evolution of diabetes medical nutrition therapy
}

\author{
M J Franz, H Warshaw, A E Daly, J Green-Pastors, M S Arnold, J Bantle
}

Postgrad Med J 2003;79:30-35

Research supports the importance of medical nutrition therapy in achieving diabetes treatment goals. For persons requiring insulin therapy, the first priority is to integrate an insulin regimen into the patient's lifestyle. For type 2 diabetes, the priority is to focus on lifestyle strategies (that is, nutrition and exercise) that will improve metabolic outcomes at diagnosis and as the disease progresses. Patients with diabetes need nutrition recommendations that are supported by scientific evidence and that can be easily understood and translated into everyday life. To achieve positive outcomes, a coordinated team effort that provides continued education and support is essential.

See end of article for authors' affiliations

Correspondence to: Marion J Franz, Nutrition Concepts by Franz, Inc, 6635 Limerick Drive Minneapolis, MN 55439, USA; MarionFranz@ aol.com

Submitted 18 June 2002 Accepted

1 October 2002

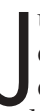
ust as changes have occurred over the past decade in medications used for treating diabetes, changes have also occurred in medical nutrition therapy (MNT) for diabetes. Before 1994, American Diabetes Association nutrition recommendations attempted to define ideal macronutrient percentages for a diabetes nutrition prescription. Then by determining an individual's energy needs based on theoretical energy requirements and using the ideal percentages for carbohydrate, protein, and fat, a nutrition prescription was ordered-for example, $1800 \mathrm{kcal}(7.52 \mathrm{MJ})$, 225 g carbohydrate (50\%), 90 g protein (20\%), and $60 \mathrm{~g}$ fat $(30 \%)$. Although individualisation was a basic principle of all recommendations, the individualisation had to be done within the confines of the nutrition prescription, which greatly limited flexibility and individualisation.

In 1994, the American Diabetes Association recommended a different approach. ${ }^{1}$ Instead of a rigid nutrition prescription, the nutrition prescription was to be based on an assessment of lifestyle changes that would assist the individual with diabetes in achieving and maintaining therapeutic goals while employing changes the patient was able and willing to make. For example, if an assessment of an overweight patient's food and nutrition history revealed an energy intake of $3000 \mathrm{kcal}$ ( $12.54 \mathrm{MJ}$ ) with $40 \%$ of energy from fat, it was recognised that it was unlikely that the patient would adhere long term to a $1500 \mathrm{kcal}(6.27 \mathrm{MJ})$ weight reduction diet. A more realistic approach would be to negotiate manageable lifestyle changes that lower energy intake and when appropriate percentage of energy from fat.

This transition to a more flexible and realistic approach to nutrition therapy continues in $2002 .^{23}$ To assist in setting priorities for MNT, the most recent American Diabetes Association nutri- tion principles and recommendations are classified according to the level of supporting evidence. A review of worldwide nutrition and diabetes research was used to determine the level of scientific support. Thus in clinical practice, priority can be given to the recommendations with the strongest supporting evidence. However, to achieve nutrition related goals requires a coordinated team effort that includes physicians, registered dietitians, diabetes educators, and the person with diabetes. Evaluation of nutrition therapy outcomes and ongoing education and support must also be a part of the care plan.

This manuscript will review MNT goals and outcomes, primary strategies to achieve these goals, current nutrition recommendations, strategies to facilitate behavioural change, and suggestions for translation of MNT to clinical practice.

\section{GOALS AND OUTCOMES OF MEDICAL NUTRITION THERAPY}

For persons with diabetes, attaining and maintaining target blood glucose goals is a beneficial outcome from MNT; however, MNT also beneficially affects lipid and lipoprotein profiles and blood pressure. Not to be forgotten is the importance of improving health through food choices and physical activity, which is the basis of all nutrition recommendations for the treatment and prevention of diabetes.

Prospective outcome studies support MNT as an effective therapy in reaching treatment goals. MNT provided by registered dietitians was associated with a $\sim 2.0 \%$ decrease in glycated haemoglobin ( $\mathrm{HbAlc}$ ) in patients with newly diagnosed type 2 diabetes, ${ }^{45}$ a $~ 1.0 \%$ decrease in HbAlc in patients with an average four year duration of type 2 diabetes, ${ }^{5}$ and a $\sim 1.0 \%$ decrease in HbAlc in patients with newly diagnosed type 1 diabetes. ${ }^{6}$ These outcomes are similar to those from oral glucose lowering medications.

In free living non-diabetic subjects, MNT which restricted saturated fats to $7 \%-10 \%$ of energy intake and dietary cholesterol to $200-300 \mathrm{mg}$ daily resulted in a $10 \%-13 \%(0.63-0.81 \mathrm{mmol} / \mathrm{l})$ decrease in plasma total cholesterol, $12 \%-16 \%$ (0.49-0.65 mmol/l) decrease in low density lipoprotein cholesterol, and $8 \% \quad(0.17-0.19$ $\mathrm{mmol} / \mathrm{l})$ decrease in triglycerides. ${ }^{7}$ Plasma high density lipoprotein cholesterol decreased by $7 \%$ with the greater saturated fat restriction, but adding exercise prevented this decrease

Abbreviations: DAFNE, dose adjustment for normal eating; $\mathrm{HbAlc}$, glycated haemoglobin; MNT, medical nutrition therapy 
Table 1 The old versus the new nutrition paradigm

Outdated nutrition advice
percentage of macronutrients)

Updated nutrition recommendations

There no longer is an ADA diet that applies to all persons with diabetes. An ADA diet can only be defined as an individualised food/meal plan based on assessment, therapy goals, and use of approaches that meet patient's needs. Diet sheets or a one time "diet instruction" rarely is sufficient to change eating habits. For people to make lifestyle changes that result in positive clinical outcomes requires both education and counselling, especially in the areas of nutrition and physical activity, and support over time

Weight loss is essential Weight loss is typically helpful but not an essential treatment for improving blood glucose. Weight loss recommendations may be a barrier for those who have tried multiple times to lose weight unsuccessfully. It is often possible to improve glucose control by changing food habits without weight loss. For those who are already at or below an appropriate weight, weight loss is not a treatment goal

Ideal body weight is the goal; this often requires a weight loss of 40 to 50 pounds Research has shown that even small amounts of weight loss can $(18-23 \mathrm{~kg})$ improve glucose, lipids, and insulin resistance in the short term. Because of the difficulty in maintaining weight loss long term, it is unknown if this is achieved long term

Sugars and sweets are forbidden, as they are more rapidly digested and absorbed Evidence from many clinical studies has demonstrated that sugars do and cause blood glucose levels to go higher than starches not increase glycaemia more than isocaloric amounts of starch. Therefore, the total amount of carbohydrate eaten is more important than the source of the carbohydrate

Protein is recommended because it slows the absorption of carbohydrates and to prevents hypoglycaemia Ingested protein does not slow the absorption of carbohydrate nor does adding protein prevent late onset hypoglycaemia or assist in the treatment of hypoglycaemia

Chromium and vitamin E often recommended because they improve blood glucose If individuals are not deficient in a micronutrient, supplements are and/or lipid levels unlikely to be beneficial. It is difficult to determine who is and who is not deficient in chromium. Supplementation with vitamin E has not been shown to be beneficial in intervention trials

"When diet and exercise fail," add medications; at this point there is no need to Type 2 diabetes is a progressive disease and MNT should always be part of the diabetes care plan; $\beta$-cells fail, not diet and exercise

Moderate reductions in dietary sodium intake $(2400$ $\mathrm{mg}$ /day) decreased blood pressure by $5 \mathrm{~mm} \mathrm{Hg}$ systolic and 2 $\mathrm{mm} \mathrm{Hg}$ diastolic in hypertensive patients and by $3 \mathrm{~mm} \mathrm{Hg}$ systolic and $1 \mathrm{~mm} \mathrm{Hg}$ diastolic in normotensive patients. Although there is wide variations in blood pressure responses, the lower the sodium intake, the greater is the lowering of blood pressure." Responses to sodium reduction may be greater in subjects who are "salt sensitive", a characteristic of many individuals with diabetes. ${ }^{10}$

\section{PRIORITISING NUTRITION STRATEGIES FOR TYPE 1 AND TYPE 2 DIABETES}

Historically, well intended but scientifically unfounded, nutrition advice has been given to patients with diabetes, such as don't eat foods containing sugar. This advice is often accompanied by an energy level "diet sheet" or a pamphlet or brochure with general guidelines. Patients often find such information difficult to understand and even more difficult to implement. Table 1 illustrates the paradigm shift that has occurred in nutrition therapy. To achieve positive clinical outcomes, individual priorities need to be defined.

\section{Type 1 diabetes}

The first priority for persons requiring insulin therapy is to integrate an insulin regimen into the patient's lifestyle. ${ }^{1-3}$ With the many insulin options now available, an insulin regimen can usually be developed which will conform to the patient's preferred meal routine and food choices. The total carbohydrate content of meals (and snacks) is the major determinant of the premeal rapid acting insulin dose and postprandial glucose response. ${ }^{11}$ After determining the amount of insulin required to cover the patient's usual meal carbohydrate, patients can be taught how to vary premeal insulin doses based on the planned carbohydrate content of the meal (insulin-to-carbohydrate ratios). This was further confirmed in the dose adjustment for normal eating (DAFNE) randomised controlled trial. In this trial individuals with type 1 diabetes were either immediately provided with the skills needed to replace insulin by matching insulin to desired carbohydrate intake on a meal to meal basis or attended the training six months later. ${ }^{12}$ DAFNE training significantly improved HbAlc with no significant increase in severe hypoglycaemia. Positive effects on quality of life, satisfaction with treatment, and psychological wellbeing, despite an increase in the number of insulin injections and in blood glucose monitoring, were also noted. For persons receiving fixed insulin regimens and not adjusting premeal insulin doses, consistency of carbohydrate intake is recommended. ${ }^{13}$

\section{Type 2 diabetes}

The emphasis of nutrition therapy for persons with type 2 diabetes is on lifestyle strategies that will improve control of hyperglycaemia, dyslipidaemia, and hypertension. ${ }^{1-3}$ Since many persons with type 2 diabetes are insulin resistant and overweight, nutrition therapy often begins with lifestyle strategies that reduce energy intake and increase energy expenditure through physical activity. These strategies should be implemented as soon as the diagnosis of diabetes or impaired glucose homoeostasis (pre-diabetes) is made.

The United Kingdom Prospective Diabetes Study revealed type 2 diabetes as a progressive disorder, and to achieve glycaemic goals, therapy-medication(s) combined with nutrition therapy-needs to be intensified over time. ${ }^{14}$ Holman in Oxford (UK) made the following observations: "Interestingly, the greatest $\mathrm{HbA}_{\mathrm{lc}}$ reduction was the fall of $2 \%$ during the first three months with intensive diet and 5\% weight loss ... The real problem is the progressive decrease in $\beta$-cell function ...we are now duty-bound to explain this to our patients at the onset ... and not to castigate them because they failed to diet". ${ }^{15}$ The initial glucose response was as much a response to the decrease in energy intake as it was to the decrease in body weight. ${ }^{4}$ Fasting plasma glucose levels $<110$ $\mathrm{mg} / \mathrm{dl}(<6.0 \mathrm{mmol} / \mathrm{l})$ were only maintained in patients who continued a restricted energy intake. In patients who 
Table 2 Key American Diabetes Association macronutrient and micronutrient nutrition guidelines

\begin{tabular}{|c|c|}
\hline Grading & Nutrition recommendations \\
\hline \multicolumn{2}{|c|}{ Carbohydrate } \\
\hline A & $\begin{array}{l}\text { - Foods containing carbohydrate from whole grains, fruits, vegetables, and low fat milk contribute essential nutrients and should be } \\
\text { included in a healthy diet }\end{array}$ \\
\hline A & $\begin{array}{l}\text { - With regard to the glycaemic effects of carbohydrates, the total amount of carbohydrate in meals or snacks is more important than } \\
\text { the source or type }\end{array}$ \\
\hline A & $\begin{array}{l}\text { - Because sucrose does not increase glycaemia to a greater extent than isocaloric amounts of starch, sucrose, and sucrose } \\
\text { containing foods do not need to be restricted by people with diabetes, however, they should be substituted for other carbohydrate } \\
\text { sources or, if added, covered with insulin or other glucose lowering medication }\end{array}$ \\
\hline A & $\begin{array}{l}\text { - Non-nutritive sweeteners are safe when consumed within the acceptable daily intake levels established by the Food and Drug } \\
\text { Administration }\end{array}$ \\
\hline \multicolumn{2}{|r|}{ 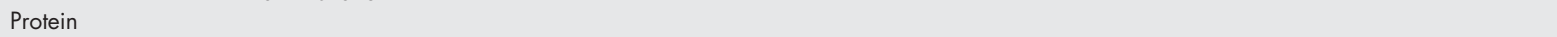 } \\
\hline B & $\begin{array}{l}\text { - Ingested protein does not increase plasma glucose concentrations in those with controlled diabetes, although ingested protein is } \\
\text { just as potent a stimulant of insulin secretion as carbohydrate }\end{array}$ \\
\hline $\mathrm{E}$ & $\begin{array}{l}\text { - For individuals with normal renal function, there is no evidence to suggest that usual protein intake }(15 \%-20 \% \text { of total daily energy } \\
\text { intake) should be modified }\end{array}$ \\
\hline $\mathrm{E}$ & $\begin{array}{l}\text { - The long term effects of diets high in protein and low in carbohydrate are unknown. Although such diets may produce short term } \\
\text { weight loss and improved glycaemia, it has not been established that weight loss is maintained long term. The long term effect of } \\
\text { such diets on low density lipoprotein (LDL) cholesterol is also a concern }\end{array}$ \\
\hline \multicolumn{2}{|r|}{ 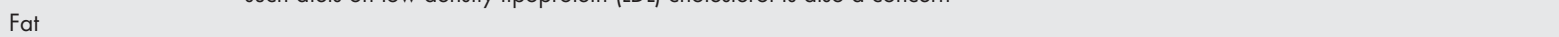 } \\
\hline A & $\begin{array}{l}\text { - In all, }<10 \% \text { of energy intake should be derived from saturated fats. Some individuals (that is, persons with LDL cholesterol } \geqslant 100 \\
\mathrm{mg} / \mathrm{dl}[2.6 \mathrm{mmol} / \mathrm{l}] \text { ) may benefit from lowering saturated fat intake to }<7 \% \text { of energy intake }\end{array}$ \\
\hline A & $\begin{array}{l}\text { - Dietary cholesterol intake should }<300 \mathrm{mg} / \text { day. Some individuals (that is, persons with LDL cholesterol } \geqslant 100 \mathrm{mg} / \mathrm{dl}[2.6 \mathrm{mmol} / \mathrm{l}] \text { ) } \\
\text { may benefit from lowering dietary cholesterol to }<200 \mathrm{mg} \text { per day }\end{array}$ \\
\hline \multicolumn{2}{|c|}{ Micronutrients } \\
\hline B & $\begin{array}{l}\text { - There is no clear evidence of benefit from supplements, including antioxidants, in people with diabetes who do not have underlying } \\
\text { deficiencies. Exceptions include folate for prevention of birth defects and calcium for prevention of bone disease }\end{array}$ \\
\hline \multicolumn{2}{|r|}{ Се } \\
\hline B & $\begin{array}{l}\text { - If individuals choose to drink alcohol, daily intake should be limited to one drink for adult women and two drinks for adult men. } \\
\text { One drink is defined as } 12 \mathrm{oz} \text { beer, } 5 \mathrm{oz} \text { wine, or } 1.5 \mathrm{oz} \text { distilled spirits }\end{array}$ \\
\hline B & - In individuals using insulin or insulin secretagogues, to reduce risk of hypoglycaemia, alcohol should be consumed with food \\
\hline
\end{tabular}

Grade is based on the American Diabetes Association grading system. The highest rank A is assigned when there is supportive evidence from multiple, well conducted studies, $B$ is an intermediate rating, $C$ is a lower rating, and $E$ represents expert consensus.

Adapted from: American Diabetes Association. Evidence-based nutrition principles and recommendations for the treatment and prevention of diabetes and related complications (position statement). Diabetes Care 2002;25:202-12.

increased their energy intake, fasting plasma glucose levels increased even if the weight loss was maintained.

Other short term studies lasting six months or less demonstrated that modest amounts of weight loss improve metabolic abnormalities in many persons with type 2 diabetes, ${ }^{16}{ }^{17}$ but not in all. ${ }^{18}$ Weight loss, especially of intra-abdominal fat, reduces insulin resistance and helps correct dyslipidaemias. However, long term data assessing the extent to which these improvements can be maintained in patients with diabetes are not available. Moreover, long term weight loss is difficult to achieve. When used alone, standard weight reduction diets providing 500 to 1000 fewer calories (2.09 to $4.18 \mathrm{MJ}$ ) than estimated energy requirements rarely lead to long term weight loss. Recent data from the Finnish Diabetes Prevention Program ${ }^{19}$ and the Diabetes Prevention Program ${ }^{20}$ demonstrate that to sustain a $5 \%-7 \%$ weight loss over a period of $2-3$ years required structured, intensive lifestyle programmes that included low fat diets, increased physical activity, ongoing educational sessions, and frequent participant contact. This type of intervention also decreased the risk for developing type 2 diabetes in persons with impaired glucose tolerance.

Physical activity improves insulin sensitivity, can acutely lower blood glucose in individuals with diabetes and may also improve cardiovascular status, but by itself has only a modest effect on weight loss. ${ }^{21}$ Physical activity is useful as an adjunct to other weight loss strategies such as dietary fat and energy reduction, is important in long term maintenance of weight loss, and decreases cardiovascular mortality. Lee et al reported on the health consequences of body fatness and cardiorespiratory fitness in relation to all-cause and cardiovascular mortality in 25000 men during eight years of follow up. ${ }^{22}$ Fit men had greater longevity than unfit men regardless of their body composition or risk factor status. Furthermore, no raised mortality risk was observed in obese men if they were physically fit and, of interest, obese fit men had a lower risk of allcause and cardiovascular mortality than lean unfit men. Farrell et al reported similar results in women. ${ }^{23}$ In a cohort of
9925 women followed up for an average of 11 years, a low level of cardiorespiratory fitness as measured by a maximal treadmill exercise test was a more important predictor of allcause mortality than baseline body mass index. Both studies support the importance of encouraging sedentary persons to become more physically active.

Teaching individuals how to make appropriate food choices in routine and special occasions, encouraging physical activity, and using data from blood glucose monitoring to evaluate short term effectiveness are important components of successful MNT for type 2 diabetes. The outcomes of nutrition interventions on glycaemic control are usually evident by six weeks to three months of therapy. ${ }^{5}$ At this point, it can be determined if MNT alone is to be continued or if medications need to be added (or adjusted) to MNT.

\section{CURRENT NUTRITION RECOMMENDATIONS}

Health professionals are frequently asked questions concerning macronutrients, micronutrients, and alcohol. Tables 2 and 3 summarise key diabetes nutrition recommendations classified according to the level of supporting evidence. ${ }^{23}$ This table can be used to provide accurate nutrition information.

\section{Carbohydrate}

Because carbohydrate is the nutrient that most affects postprandial glucose and is the major determinant of premeal insulin doses, it is addressed first. There is strong evidence to suggest that total amount of carbohydrate is more important than the source or the type of carbohydrate. The ingestion of a variety of starches or sucrose, both acutely and for up to six weeks, was shown to produce no significant differences in glycaemic response if the total amount of carbohydrate is similar. ${ }^{24}$ All patients can benefit from basic information about carbohydrates-what foods contain carbohydrates (starches, fruit, starchy vegetables, milk, sweets), average $15 \mathrm{~g}$ portion sizes, and how many servings to select for meals (and snacks if desired). 
Table 3 Key American Diabetes Association nutrition treatment considerations

\begin{tabular}{|c|c|}
\hline Grading & Nutrition guidelines \\
\hline \multicolumn{2}{|c|}{ Energy balance and obesity } \\
\hline A & $\begin{array}{l}\text { - In insulin resistant individuals, reduced energy intake and modest weight loss improve insulin resistance and glycaemia in the short } \\
\text { term }\end{array}$ \\
\hline A & $\begin{array}{l}\text { - Structured programmes which emphasise lifestyle changes including education, reduced fat (<30\% of daily energy) and energy } \\
\text { intake, regular physical activity, and regular participant contact, can produce long term weight loss on the order of } 5 \% \text { to } 7 \% \text { of } \\
\text { starting weight }\end{array}$ \\
\hline A & $\begin{array}{l}\text { - Exercise and behaviour modification are most useful as adjuncts to other weight loss strategies. Exercise is helpful in maintenance } \\
\text { of weight loss }\end{array}$ \\
\hline A & $\begin{array}{l}\text { - Standard weight reduction diets, when used alone, are unlikely to produce long term weight loss. Structured, intensive lifestyle } \\
\text { programmes are necessary }\end{array}$ \\
\hline \multicolumn{2}{|c|}{ Children and adolescents with diabetes } \\
\hline E & $\begin{array}{l}\text { - Individualised food/meal plans and intensive insulin regimens can provide flexibility for children and adolescents with diabetes to } \\
\text { accommodate irregular meal times and schedules, varying appetite, and varying activity levels }\end{array}$ \\
\hline \multicolumn{2}{|r|}{ 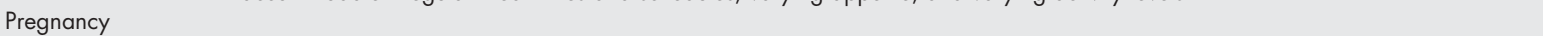 } \\
\hline $\mathrm{E}$ & - Nutrition requirements during pregnancy and lactation are similar for women with and without diabetes \\
\hline $\mathrm{E}$ & $\begin{array}{l}\text { - Medical nutrition therapy for gestational diabetes focuses on food choices for appropriate weight gain, normoglycaemia, and } \\
\text { absence of ketones }\end{array}$ \\
\hline $\mathrm{E}$ & - For some women with gestational diabetes, modest energy and carbohydrate restriction may be appropriate \\
\hline \multicolumn{2}{|r|}{ 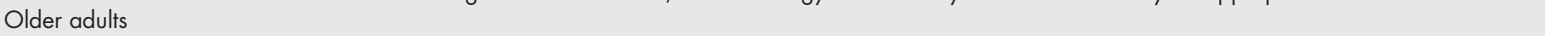 } \\
\hline A & - Energy requirements for older adults are less than for younger adults \\
\hline A & - Physical activity should be encouraged \\
\hline $\mathrm{E}$ & $\begin{array}{l}\text { - In the elderly, undernutrition is more likely than overnutrition and therefore caution should be exercised when prescribing weight } \\
\text { loss diets }\end{array}$ \\
\hline \multicolumn{2}{|c|}{ Hypoglycaemia } \\
\hline A & - Ingestion of $15-20 \mathrm{~g}$ of glucose, or to any form of carbohydrate containing glucose, is an effective treatment \\
\hline B & - Initial response to treatment should be seen in $\sim 10-20$ minutes \\
\hline $\mathrm{E}$ & - Blood glucose concentrations should be evaluated again in 60 minutes and additional treatment taken if necessary \\
\hline \multicolumn{2}{|r|}{ ( } \\
\hline A & - A reduction in sodium lowers blood pressure \\
\hline $\mathrm{E}$ & - The goal is a sodium intake of $\leqslant 2400 \mathrm{mg}$ ( $100 \mathrm{mmol}$ ) per day \\
\hline \multicolumn{2}{|r|}{ 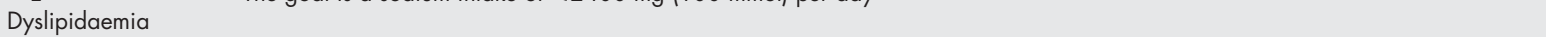 } \\
\hline B & $\begin{array}{l}\text { - For persons with raised low density lipoprotein cholesterol, saturated fatty acids and trans unsaturated fatty acids should be limited } \\
\text { to }<10 \% \text { and perhaps }<7 \% \text { of energy }\end{array}$ \\
\hline B & $\begin{array}{l}\text { - For individuals with the metabolic syndrome, improved glycaemic control, modest weight loss, dietary saturated fat restriction, } \\
\text { increased physical activity, and incorporation of monounsaturated fat, if weight loss is not a goal, may be beneficial }\end{array}$ \\
\hline \multicolumn{2}{|r|}{ 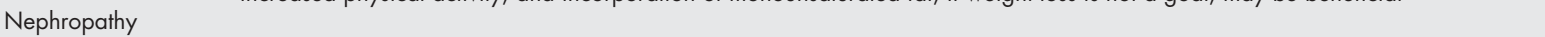 } \\
\hline C & $\begin{array}{l}\text { - In individuals with microalbuminuria, reduction of protein to } 0.8-1.0 \mathrm{~g} / \mathrm{kg} \text { body weight per day, and in individuals with overt } \\
\text { nephropathy, reduction to } 0.8 \mathrm{~g} / \mathrm{kg} \text { body weight per day, may slow the progression of nephropathy }\end{array}$ \\
\hline \multicolumn{2}{|c|}{ Prevention of diabetes } \\
\hline$A$ & $\begin{array}{l}\text { - Structured programmes which emphasise lifestyle changes including education, reduced fat and energy intake, regular physical } \\
\text { activity and regular participant contact can produce long term weight loss of 5\%-7\% of starting weight and reduce the risk for } \\
\text { developing diabetes }\end{array}$ \\
\hline B & $\begin{array}{l}\text { - All individuals, especially family members of persons with type } 2 \text { diabetes, should be encouraged to engage in regular physical } \\
\text { activity to decrease risk of developing type } 2 \text { diabetes }\end{array}$ \\
\hline
\end{tabular}

Grade is based on the American Diabetes Association grading system. The highest rank A is assigned when there is supportive evidence from multiple, well conducted studies, $B$ is an intermediate rating, $C$ is a lower rating, and $E$ represents expert consensus.

Adapted from: American Diabetes Association. Evidence-based nutrition principles and recommendations for the treatment and prevention of diabetes and related complications (position statement). Diabetes Care 2002;25:202-12.

Although differing carbohydrates do have different glycaemic responses (glycaemic index), there is limited evidence to show long term glycaemic benefit when low glycaemic index diets versus high glycaemic index diets are implemented. ${ }^{24}$ The concept of the glycaemic index is perhaps best used for fine tuning postprandial responses after first focusing on total carbohydrate. Although very large amounts of fibre (50 g) can have beneficial effects on postprandial glycaemia, it is doubtful that the majority of patients will regularly consume enough dietary fibre to see this benefit. ${ }^{25} 26$

\section{Protein}

Protein is probably the most misunderstood nutrient with inaccurate advice frequently given. Although excess amino acids may undergo gluconeogenesis, in subjects with controlled diabetes, the glucose produced minimally, if at all, enters into the general circulation. ${ }^{27}{ }^{28}$ Furthermore, protein does not slow the absorption of carbohydrate ${ }^{28}$ and does not help in the treatment of hypoglycaemia. ${ }^{29}$

\section{Fat}

Limiting intake of saturated fats and dietary cholesterol is recommended. Trans fatty acids-unsaturated fatty acids formed when vegetables oils are processed and hydrogenated-when studied independently of other fatty acids, similar to saturated fatty acids raise plasma low density lipoprotein cholesterol and intake should be restricted. To lower low density lipoprotein cholesterol, energy intake from saturated or trans fats can be reduced if weight loss is desirable or replaced with either carbohydrate or monounsaturated fat when weight loss is not a goal. The American Diabetes Association is somewhat cautious in recommending increased intake of monounsaturated or polyunsaturated fats. The concern is that a high monounsaturated fat diet selected ad libitum may lead to higher energy intakes and weight gain. In general, research suggests that low fat diets are usually associated with modest weight loss, which can be maintained as long as the diet is continued. ${ }^{30}$ With this modest weight loss, a decrease in total cholesterol and triglycerides and an increase in high density lipoprotein cholesterol are observed.

\section{Micronutrients}

There is limited evidence to recommend routine supplementation of vitamins, including antioxidants, and minerals in patients that do not have an underlying deficiency. ${ }^{2}$

\section{Alcohol}

Recommendations for alcohol intake are similar to those for the general public. Alcoholic drinks should be limited to less than two per day for men and less than one per day for 
women. ${ }^{2}$ One drink is defined as a $12 \mathrm{oz}$ beer, $5 \mathrm{oz}$ wine, or 1.5 oz of distilled spirits, each of which contain $\sim 15 \mathrm{~g}$ alcohol. Moderate amounts of alcohol when ingested with food have minimal, if any, effect on blood glucose and insulin levels. ${ }^{31}$ For individuals using insulin or insulin secretagogues, alcohol should be consumed with food to prevent hypoglycaemia. Evening consumption of alcohol can also increase the risk of hypoglycaemia the next morning, and blood glucose testing at this time can be used to determine if extra carbohydrate or a reduction in the morning insulin dose might be needed. ${ }^{32}$

\section{FACILITATING BEHAVIOUR CHANGE}

Although it is essential that people with diabetes have accurate nutrition information, information alone is not enough to change behaviour. Numerous studies have found that knowledge is not or is only weakly associated with positive outcomes related to lifestyle change. ${ }^{33}$ Several counselling and educational strategies are likely to improve the patient's ability to apply nutrition recommendations. Assessing the patient's readiness to change stage helps the health professional match therapeutic recommendations to the patient's willingness to modify their behaviour and to prioritise nutrition education topics. Using effective teaching and communication skills helps develop relationships of trust and mutual respect. Patients are then more able to hear the recommendations, participate in decision making and help develop plans that fit their situation. Focusing on behaviour change/problem solving skills ${ }^{83-35}$ allows the health care provider to address motivations, beliefs, attitudes, coping skills, and environmental support.

Individuals who hold two important beliefs are more likely to engage in effective self management behaviours than are those who do not hold these beliefs. These two beliefs to listen for are that patients: (1) consider their diabetes to be serious and (2) believe that their actions make a difference. ${ }^{35}$ An individual's self confidence in making and maintaining a change is a significant predictor of later adherence. ${ }^{36}$ Support from family and friends should be provided in the right balance; the right amount will support patient efforts without being perceived as "nagging" or intrusive, which negatively affects patient efforts to change their behaviour. ${ }^{37}$

\section{TRANSLATION TO CLINICAL PRACTICE}

With chronic illnesses such as diabetes, the role of health care providers shifts from providing direct medical care to facilitating self management of the disease by individuals with diabetes and their families. Although some physicians provide their own nutrition and physical activity education, it is a time consuming process. Many choose to use a team approach with registered dietitians and nurses (as well as other allied health team members) in their medical centre or clinic or delegate the educational and skill building components by referring to a registered dietitian and/or a diabetes education programme.

In any case, the introduction to food/meal planning and physical activity for the person with diabetes usually starts in their physician's office when they are provided with general guidelines. Endorsing and supporting lifestyle changes before referring the patient for additional education, is a simple but effective method. However, individualisation of nonpharmacological therapy based on treatment goals will be critical to achieve the desired outcomes.

To improve outcomes from MNT requires that resources be available to primary care providers and that there be financial commitment for MNT. In the United States, a barrier to providing persons with diabetes nutrition therapy on an outpatient basis has been the lack of reimbursement or coverage. Though barriers still exist, this situation has improved recently due to the passage of both federal and state laws and the recognition by some insurance companies that the coverage of this service is clinically and cost effective. At the federal level, Medicare beneficiaries with diabetes can be covered for outpatient diabetes self management training, which also includes nutrition therapy. These programmes must follow the National Standards for Diabetes Self-Management Education Programs. ${ }^{38}$ In addition, the first benefit in the United States to cover MNT for Medicare beneficiaries went into effect January 2002. The treating physician must refer the beneficiary and the service must be provided by a qualified nutrition professional (registered dietitian).

In addition, more health plans than ever before are covering diabetes self management education and nutrition therapy. In the United States, it is well worth referring patients for these services and to encourage patients to contact their health plans to determine the coverage for these services.

\section{SUMMARY}

There have been major changes in nutrition recommendations over the past decade. It is essential that all team members understand nutrition issues and guide the patient's efforts by reinforcing basic and important messages, referring patients with diabetes for MNT, promoting the importance of lifestyle changes, and providing support for the nutrition intervention process.

MNT remains essential for effective diabetes management and successful MNT involves an ongoing process of problem solving, adjustment, and readjustment. Patients must learn how to anticipate and deal with the wide variety of daily decisions they must make regarding food choices and physical activity. Healthful food choices and regular physical activity also improve overall health, an added benefit for people living with a chronic disease.

\section{ACKNOWLEDGEMENT}

The first five authors are members of a task force supported by the Diabetes Care and Education Dietetic Practice Group of the American Dietetic Association.

\section{Authors' affiliations}

M J Franz, Nutrition Concepts by Franz, Inc, Minneapolis, Minnesota H Warshaw, Hope Warshaw Associates, Alexandria, Virginia A E Daly, Springfield Diabetes and Endocrine Center, Springfield, Illinois J Green-Pastors, Virginia Center for Diabetes Professional Education, University of Virginia Health System, Charlottesville, Virginia M S Arnold, Joan Goodwin \& Associates, Inc, Diabetes Educators, Dayton, Ohio

J Bantle, Division of Endocrinology and Diabetes, Department of Medicine, University of Minnesota Medical School, Minneapolis, Minnesota

\section{REFERENCES}

1 American Diabetes Association. Nutrition recommendations and principles for people with diabetes mellitus (position statement). Diabetes Care 1994; 17:519-22.

2 American Diabetes Association. Evidence-based nutrition principles and recommendations for the treatment and prevention of diabetes and related complications (position statement). Diabetes Care 2002;25:202-12

3 Franz MJ, Bantle JP, Beebe CA, et al. Evidence-based nutrition principles and recommendations for the treatment and prevention of diabetes and related complications (technical review). Diabetes Care 2002; 25: 148-98.

4 UKPDS Group. UK Prospective Diabetes Study 7. Response of fasting plasma glucose to diet therapy in newly presenting type II diabetic patients. Metabolism 1990;39:905-12.

5 Franz MJ, Monk A, Barry B, et al. Effectiveness of medical nutrition therapy provided by dietitians in the management of non-insulin-dependent diabetes mellitus: a randomized, controlled clinical trial. J Am Diet Assoc 1995;95:1009-17.

6 Kulkarni K, Castle G, Gregory R, et al for the Diabetes Care and Education Dietetic Practice Group. Nutrition practice guidelines for type 1 diabetes mellitus positively affect dietitian practices and patient outcomes. J Am Diet Assoc 1998;98:62-70.

7 Yu-Poth S, Zhao G, Etherton T, et al. Effects of the National Cholesterol Education Program's step I and step II dietary intervention programs of cardiovascular disease risk factors: a meta-analysis. Am J Clin Nutr 1999:69:632-46.

8 Cutler JA, Follmann D, Allender PS. Randomized trials of sodium reduction: an overview. Am J Clin Nutr 1997;65(suppl 1):643S-51S. 
9 Sacks FM, Svetkey LP, Vollmer WM, et al for the DASH-Sodium Collaborative Research Group: effects on blood pressure of reduced dietary sodium and the dietary approaches to stop hypertension (DASH) diet. N Engl J Med 2002;344:3-10.

10 Tuck M, Corry D, Trujillo A. Salt-sensitive blood pressure and exaggerated vascular reactivity in the hypertension of diabetes mellitus. Am J Med 1991;88:210-16

11 Rabasa-Lhoret R, Garon J, Langelier H, et al. The effects of meal carbohydrate content on insulin requirements in type 1 diabetic patients treated intensively with the basal bolus (ultralente-regular) insulin regimen. Diabetes Care 1999.22:667-73.

12 DAFNE Study Group. Training in flexible, intensive insulin management to enable dietary freedom in people with type 1 diabetes: dose adjustment for normal eating (DAFNE) randomised controlled trial. BM 2002;325:746-51.

13 Wolever TMS, Hamad S, Chiasson J-L, et al. Day-to-day consistency in amount and source of carbohydrate intake associated with improved

14 UK Prospective Diabetes Study Group. Intensive blood-glucose control with sulphonylureas or insulin compared with conventional treatment and risk of complications in patients with type 2 diabetes (UKPDS 33). Lancet 1998;352:837-53

15 Bloomgarden ZT. European Association for the Study of Diabetes Annual Meeting, 1999. Diabetes Care 2000;23:1016.

16 Wing RR, Koeske R, Epstein LH, et al. Long-term effects of modest weight loss in type II diabetic patients. Arch Intern Med 1987:147:1749-53.

17 Markovic TP, Jenkins AB, Campbell LV, et al. The determinants of glycemic responses to diet restriction and weight loss in obesity and NIDDM. Diabetes Care 1998:21:687-94.

18 Watts NB, Spanheimer RG, DiGirolamo M, et al. Prediction of glucose response to weight loss in patients with non-insulin-dependent diabetes mellitus. Arch Intern Med 1990;150:803-6.

19 Tuomilehto J, Lindstrom J, Eriksson JG, et al. Prevention of type 2 diabetes mellitus by changes in lifestyle among subjects with impaired glucose tolerance. N Engl J Med 2001;344:1343-50.

20 Diabetes Prevention Program Research Group. Reduction in the incidence of type 2 diabetes with lifestyle intervention or mefformin. $N$ Engl J Med 2002;346:393-403.

21 Boulè NG, Haddad E, Kenny GP, et al. Effects of exercise on glycemic control and body mass index in type 2 diabetes mellitus. A meta-analysis of controlled clinical trials. JAMA 2001·286:1218-27.

22 Lee DC, Blair SN, Jackson AS. Cardiorespiratory fitness, body composition, and all- cause and cardiovascular disease mortality in men. Am J Clin Nutr 1999;69:373-80

23 Farrell SW, Braun LA, Barlow CE, et al. The relation of body mass index, cardiorespiratory fitness, and all-cause mortality in women. Obes Res 2002;10:417-23.
24 Franz MJ. Carbohydrate and diabetes: is the source or the amount of more importance? Current Diabetes Reports 2001;1:177-86.

25 Lafrance L, Rabasa-Lhoret R, Poisson D, et al. The effects of different glycaemic index foods and dietary fibre intake on glycaemic control in type 1 diabetic patients on intensive insulin therapy. Diabetic Med 1998; 15:972-8.

26 Chandalia M, Garg A, Luthohann D, et al.. Beneficial effects of a high dietary fiber intake in patients with type 2 diabetes. N Engl J Med 2000:342:1392-8

27 Gannon MC, Nuttall JA, Damberg G, et al. Effect of protein ingestion on the glucose appearance rate in people with type 2 diabetes. J Clin Endocrinol Metab 2001;86:1040-7.

28 Nuttall FQ, Mooradian AD, Gannon MC, et al. Effect of protein ingestion on the glucose and insulin response to a standardized oral glucose load. Diabetes Care 1984;7:465-70.

29 Gray RO, Butler PC, Beers TR, et al. Comparison of the ability of bread versus bread plus meat to treat and prevent subsequent hypoglycemia in patients with insulin-dependent diabetes. J Clin Endocrinol Metab 1996;81:1508-11

30 Lichtenstein $\mathbf{A H}$, Ausman LM, Carrasco W, et al. Short-term consumption of a low fat diet beneficially affects plasma lipid concentrations only when accompanied by weight loss. Arterioscler Thromb 1994;14:1751-60.

31 Koivisto VA, Tulokas S, Toivonen M, et al. Alcohol with meal has no adverse effects on postprandial glucose homeostasis in diabetic patients. Diabetes Care 1993;16:1612-14.

32 Turner BC, Jenkins E, Kerr D, et al. The effect of evening alcohol consumption on next-morning glucose control in type 1 diabetes. Diabetes Care 2001:24:1888-93.

33 Glasgow RE, Osteen VL. Evaluating diabetes education: are we measuring the right outcomes? Diabetes Care 1992;15:1423-32.

34 Maryniuk MD. Counseling and education strategies for improved adherence to nutrition therapy. In: Franz M, Bantle JP, eds. American Diabetes Association guide to medical nutrition therapy for diabetes. Alexandria, VA: American Diabetes Association, 1999: 369-86.

35 Glasgow RE, Eakin EG. Dealing with diabetes self-management. In: Anderson BJ, Rubin RR, eds. Practical psychology for diabetes clinicians. Alexandria, VA: American Diabetes Association, 1996: 53-62.

36 Kavanagh DJ, Gooley S, Wilson PH. Prediction of adherence and control in diabetes. J Behav Med 1993;16:509-22.

37 Boehm S, Schlenk EA, Funnell MM et al. Prediction of adherence to nutrition recommendations in people with NIDDM. Diabetes Educ 1997:23:157-65.

38 Mensing C, Boucher J, Cypress $M$, et al. National standards for diabetes self-management education (standards and review criteria). Diabetes Care 2000;23:682-9. 